\title{
Cognitive Behavioural Intervention of Avoidant Personality Disorder - A Case Study
}

\author{
Bidita Bhattacharya, Ph.D., M.Phil., M.Sc. \\ Assistant Professor and Head, Department of Clinical Psychology \\ Institute of Psychiatry, 7, D. L. Khan Road, Kolkata, West Bengal, India \\ Email : bidita.bhattacharya@gmail.com, +91 9831095984, +91 3325238099
}

\section{ABSTRACT}

Avoidant personality disorder is characterized by pervasive behavioural, emotional and cognitive avoidances. There are evidences that both psychodynamic therapy and cognitive behavior therapy are effective treatments of personality disorders. In the current case study a 21 year old male with a diagnosis of avoidant personality disorder was taken for psychological intervention through cognitive behavioural approach. Total 33 sessions were held over a period of four months. The client reported significant improvement in therapy. His functioning level and social skills were improved and was looking forward to address his problems in more optimistic approach.

\section{INTRODUCTION}

Avoidant personality disorder is characterized by pervasive behavioural, emotional and cognitive avoidances, even when personal goals or wishes are foiled by such avoidance. Cognitive themes that contribute avoidance include self-deprecation, beliefs that unpleasant thoughts or emotions are intolerable, and an assumption that exposure of the "real self" to others or assertive self-expression will be met with rejection (1).

There are evidences that both psychodynamic therapy and cognitive behavior therapy are effective treatments of personality disorders. Since the number of studies was limited, the conclusions that can be drawn are only preliminary (2). However, there are studies where avoidant personality disordered individuals who completed a 10 week behavioual group treatment programme displayed significantly greater improvement (3) Patients with avoidant personality disorder display varied responses to behavioral treatment. They differ in terms of their interpersonal problem "profiles" and that these differences influence response to behavioral intervention (4). Hence, current case was decided to manage from both the aspects, cognitive as well as behavioural.

\section{SUMMARY OF THE CASE}

A 21 year old male came with his mother with the complaints of feeling fearful, anxious and having discomfort in social situation and avoiding the same. Theclient reported of being reserved and shy since childhood. He always avoided places that had a gathering of people and reported feeling uncomfortable in the presence of many people. 


\section{Cognitive Behavioural Intervention of Avoidant Personality Disorder - A Case Study}

He never liked attending social events and if at all he needs to attend such situation he would keep himself isolated. He would also feel inferior and would lack confidence in himself in almost all situations. He would become apprehensive in most social situations and would worry about others making adverse comments about him or ridiculing him in some way. He often would fear about doing something embarrassing and being laughed at, and would prefer avoiding socializing. He would not be able to interact and communicate with others, even if other people had initiated the interactions. He would merely reply to the questions and try to end the conversation as soon as possible. As reported, he never liked any kind of attention on him. For this reason during his schooldays he would never raised his hand to questions even if he knew the correct answer.Hewould feel uncomfortable standing in front of the entire class and would mostly fumble in his speech and even sometimes forget the answer. Currently he is persuing his study in under graduation course and reporting same difficulty which he used to have during his school days. He is unable to participate in class and unable to get along with his classmates. His mother was also concerned about his interpersonal problem. He never participated in sporting events in school as well as in college.He also reported of being sad due to his problems.

The client did not report of having fearfulness in a particular object or situation, any repetitive intrusive thought and free-floating anxiety. His problems are rather pervasive and present since early childhood.

The client was born of full term normal delivery and elder between two siblings. His father was reported to be strict and stern. He would scold the client terribly whenever he was undisciplined and disobedient, even in small issues. Father had been overcritical and punitive and client maintained a distant relationship with his father, and reported being scared of him. The mother was reported to be little more lenient than father, however, overcritical. He feels better attached with his mother. His parents reportedly often compared him unfavourably to his other cousins or friends in terms of his academic performance or general behaviours, which further contributed to his sense of inadequacy and sadness of mood. Also, he felt his parents always disagreed with him and did not attempt to understand his perspective. They would discard his views in most of the time. As a result he did not talk much to both of them, rather avoid interactions with them to avoid conflicts. However, he would feel comfortable with his grandparents in terms of communication and emotional support.

On Mental status examination he appeared well kempt and tidy, attitude toward clinician was cooperative and rapport was established easily. His speech was relevant, coherent and goal directed, however, output was less. His cognitive functions were adequate. His mood and affect was depressed and anxious.

\section{DIAGNOSIS}

F60.6 Anxious [Avoidant] Personality Disorder

\section{CONCEPTUALIZATION AND FORMULATION OF THE CASE}

The client holds deep seated negative beliefs about himself, others and unpleasant emotional experiences. These beliefs had stem from his childhood interactions with rejecting and critical significant persons in his life (i.e., his parents). He sees himself as inadequate and worthless, others as critical and rejecting. His dysphoric and anxious emotions are overwhelming and at times intolerable. Socially, he avoids situations in which other people could get close and discover the "real" them. Behaviourally, he avoids tasks that would engender thoughts that make him feel uncomfortable. Cognitively, he avoids thinking about matters that produce dysphoria and anxiety. His tolerance for discomfort is quite low and he relies on distractions and avoidance whenever he begin to feel anxious and sad. He is unhappy with his current state, but feel incapable of changing through his own efforts. 
Cognitive Behavioural Intervention of Avoidant Personality Disorder - A Case Study

This case has been formulated from cognitive | behavioural approach (given below):
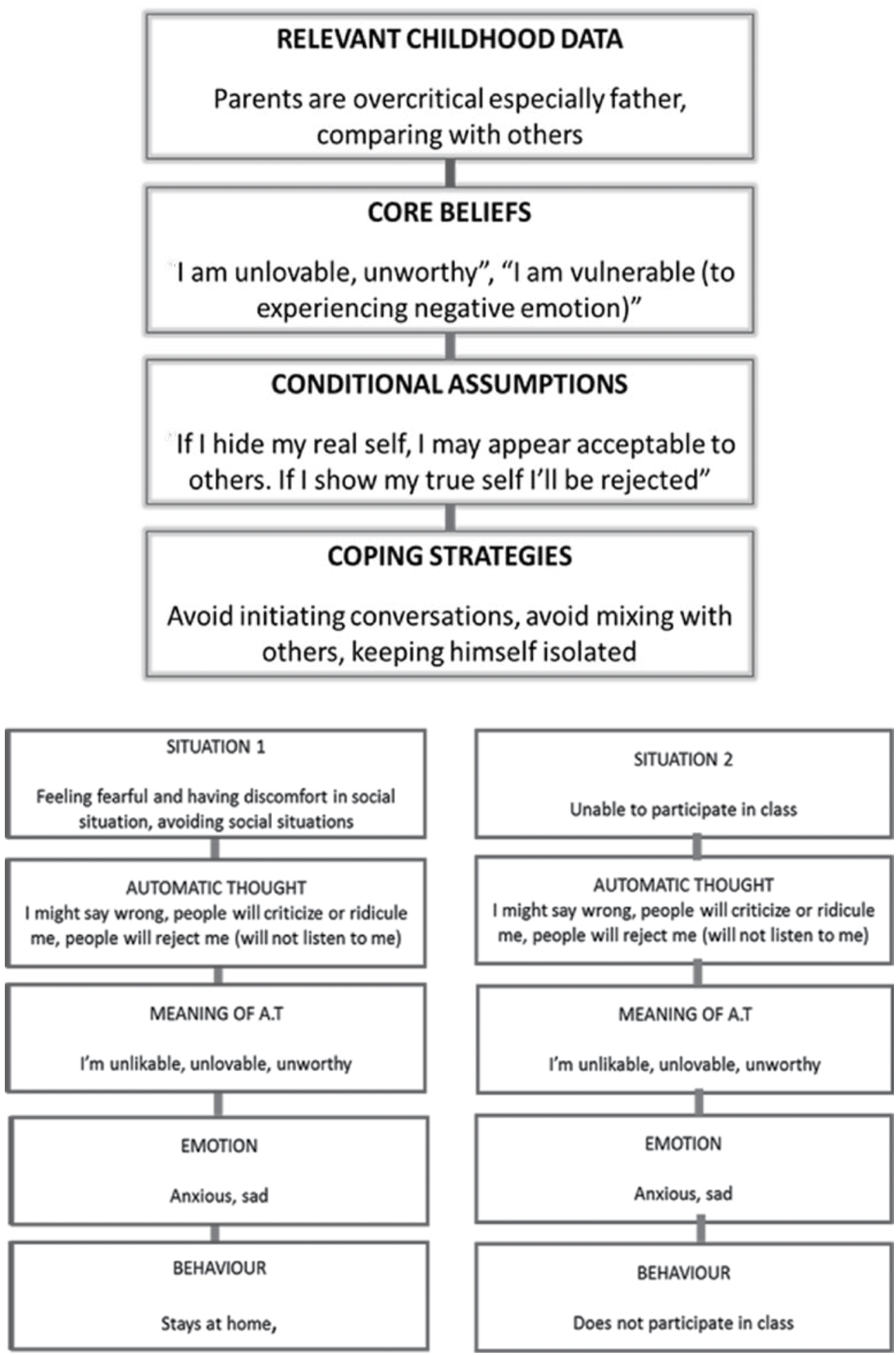


\section{ASSESSMENT}

The client was assessed by administering International Personality Disorder Evaluation (IPDE), which confirms the diagnosis of anxious (avoidant) personality disorder.

\section{INTERVENTION}

Intervention of this case was done in three phases in cognitive behavioural approach. Weekly two sessions were held. The duration of each session was 45 minutes to one hour. Total 33 sessions were held over a period of four months. The client was referred from Psychiatry OPD for psychological intervention without prescribing any medication. The client and his mother were highly engaged and cooperative for therapy.

\section{PHASE I : CRISIS \\ MANAGEMENT (16 Sessions)}

In this phase current situation was addressed. The focus was on managing current disturbing condition and improving his activities of daily living.

\section{SESSIONS 1-3 : Psychoeducation}

At the very beginning after taking detailed case history, the client and his mother were psychoeducated in detail. This was done in cognitive behavioural approach, where cognitive behavioural model of illness was explained. The client was explained about the condition, and informed about their prevalence in the general population. The possible causes of the conditions were discussed briefly. Also he was briefly told about the process and outcome of the illness and therapy, and what to expect from therapy. It was discussed that not all symptoms and conditions can be targeted at once and will be conducted in three phases. The need for regular and continued therapy sessions was discussed.

\section{SESSIONS 4-6 :}

\section{Relaxation Training}

After discussing the rationale and implication of relaxation, the client was taught Jacobson's
Progressive Muscular Relaxation (JPMR). JPMR was introduced both as a method of modifying autonomic arousal and as a necessary part of systematic desensitization. The client was also given the homework assignment of practicing relaxation at home.

\section{SESSIONS 7 AND 8 :}

Review of Relaxation Training and Lierarchy Construction

The client was asked to perform the relaxation exercise during the therapy session in front of the therapist. He was able to follow the correct process and timings as well. The client was found to become adequately proficient at the exercise at the end of session 7.Then next step for systematic desensitization was introduced, i.e., hierarchy construction. Two separate hierarchies were made for his anxieties related to classroom as well as in social situations.

\section{SESSIONS 9 - 16 :}

\section{Systematic Desensitization Procedure}

The client was able to participate adequately in this procedure. Two hierarchies were done separately.

\section{OUTCOME OF PHASE I :}

The client was able to understand his current condition as well as his illness. He was also able to do relaxation which reportedly made him able to relax himself. He was also able to attend his classes and few social situations.

\section{PHASE II :}

\section{Short Term Therapy and Early Stages of} Long Term Therapy (5 Sessions)

In this phase maladaptive cognitive styles and cognitive errors were elicited. Also associated maladaptive interpersonal pattern was elicited and subsequently addressed. 
SESSION 17 AND 18 :

\section{Building and Maintaining Collaborative Relationship}

Priority was given to building and maintaining the alliance because a collaborative therapeutic relationship is inherently supportive and central to managing core pathology. In these sessions the client was encouraged to accept help and to develop the sense of optimism and hope. Client's automatic thoughts were elicited and evaluated. He was encouraged to evaluate their negative beliefs about the therapy relationship in light of these past experiences with the therapist.He was also allowed to test his own automatic thoughts by engaging him in small experiments.

\section{SESSION 19 : Validation}

In this session the client was given adequate time to express his affects and to describe his negative as well as positive experiences. This was intended to make problematic experiences, responses, and situations understandable as a part of the more general search for meaning. Also, client was helped to see the behavior was adaptive in the circumstances in which it developed and simultaneously indicated the possibility of change.

\section{SESSIONS 20 AND 21 :}

\section{Managing Ambivalence}

After the last session, the client started showing ambivalence about change. Although he recognized that change is desirable and even necessary, but at the same time it evoked fear and resentment of the struggle to deal with problems. This ambivalence was intervened by discussing the relative strengths of the positive and negative aspects of change. The discrepancy was indicated and explained between current experience and the way he would like to experience the self and the world. He was also encouraged to consider the benefits of change.

\section{OUTCOME OF PHASE II :}

The client was able to understand cognitive errors and was able to implement suggested strategies as reported by him.

\section{PHASE III :}

\section{Long Term Therapy (12 Sessions)}

In this phase core beliefs and enduring maladaptive interpersonal patterns as well as interpersonal problems had been addressed.

\section{SESSIONS $22-26$ :}

\section{Overcoming Social Avoidance}

Core beliefs and underlying assumptions: The client was found to have several long-standing dysfunctional beliefs, which were interfering with social functioning. Those may have been developed due to his childhood experiences of critical comments and rejection experiences from his parents. He also had developed certain conditional assumptions to explain his negative interactions.

In these sessions the client was assisted to understand the developmental roots of the negative beliefs and assumptions, fear of rejection, and selfcriticism. Particular attention was paid how these beliefs were helpful at some earlier time in his life. Then alternative new belief had been identified that he wishes were true. Old and new beliefs were tested through experiments, guided observation, and role-play reenactments of early schema-related incidences. Finally he was directed to begin to notice and remember incidences about himself and their social experiences that support the new, more desirable beliefs.

\section{SESSIONS 27 - 31 :}

\section{Overcoming Cognitive and Emotional Avoidance}

The client was experiencing a range of dysphoric moods and was avoiding thinking about things that caused unpleasant emotions. He was avoiding experiencing negative emotions between and during therapy sessions.

These sessions were focused on increasing emotional tolerance. Through guided discovery he was able to understand the disadvantages of avoidance and 


\section{Cognitive Behavioural Intervention of Avoidant Personality Disorder - A Case Study}

the likelihood that positive emotions will not be fully experienced. The origin of the avoidance of dysphoria which was initiated in childhood when he was indeed more vulnerable and less able to cope with the unpleasant or painful feelings, was explored. The client was encouraged to evoke emotions in the session by discussing experiences about which he reported discomfort.

Then the client was directed back to the feelings in order to begin to identify and test the beliefs leading to the avoidance. The client was further helped to become aware of and "stay with" her distressing thoughts.

\section{SESSIONS 32 AND 33 : Skill Building}

The client's skill deficits had been addressed in these sessions. His skill deficits had been taken place due to his impoverished social experiences. His skill training had begun with non-verbal cues like eye contact, posture, and smiling. He was also suggested to practice at home, and then in low risk social situations.

\section{OUTCOME OF PHASE III :}

The client reported significant reduction of his symptoms. There were subjective feeling of improvement reported especially in classroom situation. He was also reportedly able to look forward to attend social situations.

\section{DISCUSSION}

Avoidant personality disorder is a syndrome characterized by long standing pattern of social anxiety and withdrawal, sensitivity to social criticism, and low self-esteem. Current case was referred for psychological intervention without prescribing any medication. This was planned to intervene through cognitive behavioural approach. In this case, behavioural modification was planned in first phase of the therapy. The focus of the initial 16 sessions was his daily living activities, which were getting impacted due to his problem. His performance in class and his social interaction, which were significantly impaired, had been addressed in this phase. Based on the subjective report of improvement of his behaviours in class and social situations, his cognitive errors were identified and addressed in second phase of therapy. This phase was relatively shorter. In third phase was the longer term therapy, which included 12 sessions. In this phase the focus was on cognitive and behaviouralskill building. Social, cognitive and emotional avoidances were addressed as well as skill training was done.

In this case, the client reported significant improvement over a period of four months. His functioning level improved and was looking forward to address his problems in more optimistic approach.

\section{REFERENCE}

1. Beck AT, Freeman A, Davis DD. Cognitive therapy of personality disorder (2nd Ed.). New York \& London: The Guilford Press; 2004. p. 293 - 319.

2. Leichsenring F, Leibing E. The effectiveness of psychodynamic therapy and cognitive behavior therapy in the treatment of personality disorders: a meta-analysis.Am Psychiatric Assoc. 2005; 3(3): 417428 .

3. Alden L. short-term structured treatment for avoidant personality disorder.J. Consult. Clin. Psychol. 1989; 57(6) : 756-764

4. Alden LE, Capreol MJ. Avoidant personality disorder : Interpersonal problems as predictors of treatment response. Behav. Ther.1993; 24(3) : 357-376. 